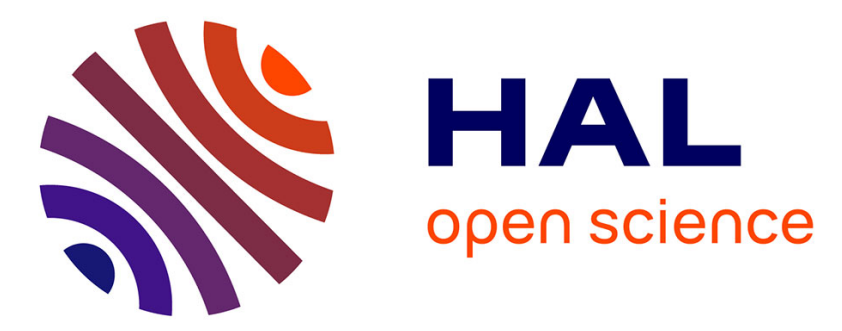

\title{
The steady state mechanism of cytochrome c oxidase: redox interactions between metal centres
}

Maria G Mason, Peter Nicholls, Chris E Cooper

\section{To cite this version:}

Maria G Mason, Peter Nicholls, Chris E Cooper. The steady state mechanism of cytochrome c oxidase: redox interactions between metal centres. Biochemical Journal, 2009, 422 (2), pp.237-246. 10.1042/BJ20082220 . hal-00479128

\section{HAL Id: hal-00479128 https://hal.science/hal-00479128}

Submitted on 30 Apr 2010

HAL is a multi-disciplinary open access archive for the deposit and dissemination of scientific research documents, whether they are published or not. The documents may come from teaching and research institutions in France or abroad, or from public or private research centers.
L'archive ouverte pluridisciplinaire HAL, est destinée au dépôt et à la diffusion de documents scientifiques de niveau recherche, publiés ou non, émanant des établissements d'enseignement et de recherche français ou étrangers, des laboratoires publics ou privés. 


\title{
The steady state mechanism of cytochrome $c$ oxidase: redox interactions between metal centres
}

\author{
Maria G. Mason, Peter Nicholls \& Chris E. Cooper \\ Department of Biological Sciences, \\ University of Essex, Colchester, \\ Essex CO4 3SQ, UK
}

Page header title: The steady state mechanism of cytochrome $c$ oxidase

\section{Email for correspondence ccooper@essex.ac.uk}

\section{Synopsis}

The steady state behaviour of isolated mammalian cytochrome $c$ oxidase was examined by increasing the rate of reduction of cytochrome $c$. Under these conditions the enzyme's 605 (haem a), 655 (haem $\left.a_{3} / \mathrm{Cu}_{\mathrm{B}}\right)$ and $830 \mathrm{~nm}\left(\mathrm{Cu}_{\mathrm{A}}\right)$ spectral features behaved as if they were at near equilibrium with cytochrome $c(550 \mathrm{~nm})$. This has implications for non-invasive tissue measurements using visible $(550,605,655 \mathrm{~nm})$ and near infrared $(830 \mathrm{~nm})$ light. The oxidised species represented by the $655 \mathrm{~nm}$ band is bleached by the presence of oxygen intermediates $(\mathrm{P}$ and $\mathrm{F}$ ) or by reduction of haem $a_{3}$ or $\mathrm{Cu}_{\mathrm{B}}$. However, at these ambient oxygen levels (far above the enzyme $\mathrm{K}_{\mathrm{m}}$ ), the populations of reduced haem $a_{3}$ and the oxygen intermediates were very low $(<10 \%)$. We therefore interpret $655 \mathrm{~nm}$ changes as reduction of the otherwise spectrally invisible $\mathrm{Cu}_{\mathrm{B}}$ centre. We present a model where small anti-cooperative redox interactions occur between haem $a-\mathrm{Cu}_{\mathrm{A}}-\mathrm{Cu}_{\mathrm{B}}$ (steady state potential ranges: $\mathrm{Cu}_{\mathrm{A}} 212-258 \mathrm{mV}$; haem $a: 254-281 \mathrm{mV}$; $\mathrm{Cu}_{\mathrm{B}} 227-$ $272 \mathrm{mV}$ ). Contrary to static equilibrium measurements, in the catalytic steady state there are no high potential redox centres $(>300 \mathrm{mV})$. We find that the overall reaction is correctly described by the classical model in which the Michaelis intermediate is a ferrocytochrome $c$-enzyme complex. However, the oxidation of ferrocytochrome $c$ in this complex is not the sole rate-determining step. Turnover is instead dependent upon electron transfer from haem $a$ to haem $a_{3}$, but the haem $a$ potential closely matches cytochrome $c$ at all times. 


\section{Introduction}

Cytochrome $c$ oxidase (cytochrome $a a_{3}$ ) of eukaryotes and some prokaryotes catalyses the following reaction (equation 1 ):

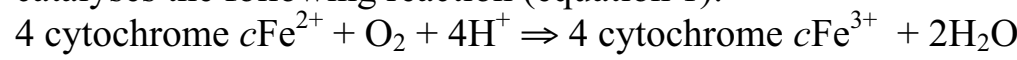

This can be broken down into three sub-reactions (scheme 1)

SUBSTRATE BINDING

(iii) PRODUCT DISSOCIATION cyt. $c \mathrm{Fe}^{2+}+$ oxidase $\Leftrightarrow$ cyt. $c \mathrm{Fe}^{2+}$ oxidase

cyt. $c \mathrm{Fe}^{2+}$ oxidase $+\mathrm{H}^{+}+{ }^{1} / 4 \mathrm{O}_{2} \Rightarrow$ cyt. $c \mathrm{Fe}^{3+}$ oxidase $+{ }^{1} / 2 \mathrm{H}_{2} \mathrm{O}$ cyt. $c \mathrm{Fe}^{3+}$ oxidase $\Leftrightarrow$ cyt. $c \mathrm{Fe}^{3+}+$ oxidase

Its kinetic mechanism can be treated as a two substrate process in which the enzyme accumulates electrons from the first substrate and transfers them to the second. Classical kinetic studies determined 'Michaelis' constants for both cytochrome $c$ and oxygen, an inhibitory constant for product ferricytochrome $c$, and a maximal turnover at high concentrations of oxygen and reduced cytochrome $c\left(c^{2+}\right)$. These studies were all consistent with the relatively simple mechanism of scheme 1. Models of this kind, originally devised by Minnaert and others [1] in the early sixties, continue in use today. Thus we have ourselves successfully used a version of this model to analyse the inhibition of cytochrome $c$ oxidase by NO [2].

However, it has been known for some time that the detailed mechanism of the enzyme must be more complicated than that of scheme 1 if only because the overall reaction (equation 1) involves four molecules of the reducing substrate for every single oxygen molecule taken up. Partial reactions of the enzyme with only one of the two substrates have therefore also been the subject of numerous more recent studies. Figure 1 summarises the reaction steps conventionally thought to be involved. Ferrocytochrome $c$ binds to the enzyme, reacting primarily with a site on subunit II [3]. An electron is then transferred reversibly to $\mathrm{Cu}_{\mathrm{A}}$ [4], the cuprous (reduced) form of which in turn equilibrates with haem $a$. Both these intramolecular redox steps are considerably faster than the overall reaction rate. Entry of a second electron (Fig. 1) involves either the reduction of the bound (now oxidized) cytochrome $c$ or its dissociation and replacement by a second ferrocytochrome $c$ molecule [5]. The second electron reduces $\mathrm{Cu}_{\mathrm{A}}$ again transiently and then adds the second reducing equivalent to the haem $a / \mathrm{Cu}_{\mathrm{B}}$ pair. The fully reduced binuclear centre then reacts with oxygen through a series of intermediates (A, P \& F), which ultimately return the enzyme to the ferric-cupric state [6].

The enzyme turns over with cytochrome $c$ at a rate apparently dependent upon the redox state of $c$, acting as if the limiting rate was $c^{2+} a a_{3} \Rightarrow c^{3+} a a_{3}{ }^{-}$with oxidised cytochrome $c$ acting as a product inhibitor. This results in so-called Smith-Conrad kinetics $[1,7]$ where the oxidation of substrate, reduced cytochrome $c$, is strictly exponential (first order), the rate being directly proportional at all times to the concentration of reduced cytochrome $c$. The $\mathrm{K}_{\mathrm{m}}$ for ferrocytochrome $c$ oxidation, the $\mathrm{K}_{\mathrm{i}}$ for ferricytochrome $c$ inhibition, and the $\mathrm{K}_{\mathrm{D}}$ for ferrocytochrome $c$ binding to reduced enzyme and ferricytochrome $c$ binding to oxidized enzyme, all have similar values $[5,8]$. The $\mathrm{K}_{\mathrm{m}}$ for oxygen [9] is very small $(1 \mu \mathrm{M}$ or lower). Consequently at ambient air oxygen levels in vitro, though maybe not in vivo [10], the levels of the oxygen-reactive ferrous haem $a_{3}$ species are very low $[11,12]$.

However, the measured partial rates appear inconsistent with the simple overall model of scheme 1. In particular the very rapid electron transfer steps from cytochrome $c$ to the other redox centres are difficult to conceptualise in a model where the redox state of cytochrome $c$ solely controls turnover. The purpose of this paper is therefore to marry the steady state kinetic data with the partial reaction kinetic data. For example can rapid equilibration be assumed between bound $c$, haem $a, \mathrm{Cu}_{\mathrm{A}}$ and possibly $\mathrm{Cu}_{\mathrm{B}}$ in the steady state, as predicted by the partial reaction kinetic data on the individual reaction steps? Is the observed steady state behaviour at different flux levels (\% reduction of cytochrome $c$ ) consistent with such kinetics and with the steady state levels of the spectral species observed during turnover? These questions are key when building up systems 
models of mitochondria and oxygen consumption $[13,14]$, especially those that report on the levels of spectroscopically-detectable enzyme species [15].

We have therefore re-examined the behaviour of the isolated (detergentsolubilised) mammalian enzyme, focusing on the spectroscopically-detectable oxidase species formed during turnover. In particular we have been concerned to study the relationship between the steady state of ferrocytochrome $c$ and the haem $a$ and $\mathrm{Cu}_{\mathrm{A}}$ centres of the oxidase as well as the population of binuclear centre intermediates under conditions of both fast and slow turnover. We conclude that the overall reaction can indeed be correctly described by scheme 1, even though the oxidation of ferrocytochrome $c$ in its complex with the enzyme is not the sole rate-determining step for the reaction. We also find that the steady state populations of other states, including $\mathrm{A}, \mathrm{P}$ and $\mathrm{F}$, are very low at ambient levels of oxygen provided the systems are kept strictly peroxide-free. 


\section{Experimental}

\section{Enzyme preparation}

Beef heart cytochrome $c$ oxidase was purified by the method of Yonetani [16], except the solubilisation buffer contained $0.1 \%$ lauryl maltoside ${ }^{1}$ (n-Dodecyl $\beta$-D-maltoside) instead of $1 \%$ Emasol. Total haem concentrations were calculated using $\Delta_{605-630}=27,000 \mathrm{M}^{-1} \mathrm{~cm}^{-1}$ for the dithionite reduced minus oxidised enzyme.

\section{Reagents and solutions}

Horse heart cytochrome $c$ was from Sigma (C-7752) and its concentration was calculated using $\Delta_{550-540}=21,200 \mathrm{M}^{-1} \mathrm{~cm}^{-1}$ for the dithionite reduced minus oxidised enzyme. Other reagents were AnalaR or better.

\section{Steady state experiments}

Cytochrome $c$ oxidase steady state measurements were made with $6.5 \mu \mathrm{M}$ cytochrome $c$ oxidase, 10 $\mu \mathrm{M}$ cytochrome $c$ and up to $40 \mathrm{mM}$ ascorbate as initial reductant. After full reduction of the cytochromes, the solution was brought to an aerobic steady state by addition of $\mathrm{H}_{2} \mathrm{O}_{2}$ ( $\mu \mathrm{M}$ to $\mathrm{mM}$ concentrations) in the presence of a catalytic amount of catalase ( $200 \mathrm{nM}$ concentration unless otherwise indicated). The steady state level of reduction was increased by adding TMPD ${ }^{1}(\mu \mathrm{M}$ to $\mathrm{mM}$ concentrations). For spectral deconvolution in the NIR region, some experiments were performed at higher cytochrome concentrations at the same oxidase $/ c$ ratio. Unless stated to the contrary, experiments were performed at $30^{\circ} \mathrm{C}$ in $0.1 \mathrm{M} \mathrm{KPi}$ with $0.1 \%$ lauryl maltoside and at $\mathrm{pH}$ 7.4. Spectra were acquired simultaneously, every 1-5 s, using a Hewlett Packard HP 8453 diode array spectrophotometer.

\section{Analysis of steady state data}

Redox changes of cytochrome oxidase metal centres and cytochrome $c$ were monitored at the wavelengths shown in Table 1. Kinetic traces for each centre were converted to fractional reduction using the ascorbate reduced (anaerobic) minus oxidised absorbance changes for $\mathrm{Cu}_{\mathrm{A}}$, the binuclear centre and cytochrome c. For haem $a$, only $85 \%$ of the ascorbate reduced minus oxidised value was used as $15 \%$ of the absorbance change at $605-630 \mathrm{~nm}$ is due to haem $a_{3}$ reduction upon anaerobiosis. Absorbance changes for $\mathrm{Cu}_{\mathrm{A}}$, haem $a$ and the binuclear centre were corrected for cytochrome $c$ spectral contributions by first measuring the cytochrome $c$ redox state and then using the experimentally determined extinctions coefficients shown in Table 1. Cytochrome $c$ oxidase prepared by the Yonetani method is in the "resting" state prior to initial reduction; therefore data acquired before this point were not used in the analysis.

\section{Modelling}

Experimental data were fitted to the appropriate interactive equations using the Solver ${ }^{\mathrm{TM}}$ function in Excel $^{\mathrm{TM}}$ [17]. In Fig. 7 each data set was fitted to a model involving two component species, one of high and the other low potential; the proportion of the two components being allowed to vary during fitting. Fits were performed using non linear regression in the software package Kaleidagraph ${ }^{\mathrm{TM}}$. Thus in Fig. 7 (and supplementary figures 2 and 3 ) the cytochrome $a, \mathrm{Cu}_{\mathrm{A}}$ and 655 $\mathrm{nm}$ species are treated as separate components and the lines plotted independently of each other. A total of 9 parameters were thus used to fit the data. But in Fig. 9 the three data sets were fitted jointly according to the model of Fig. 8. For three redox species able to exist in fully oxidized, oneelectron reduced, two-electron reduced and fully reduced states, and in which the redox potential of any component can be modified by the redox states of the other two components there may be up to seven independent potentials (generating the total of twelve equilibria shown in Fig. 8). The Solver ${ }^{\mathrm{TM}}$ function in Excel $^{\mathrm{TM}}$ was then used to obtain the best fit to the data sets by allowing seven redox potentials to vary. 


\section{Results and Discussion}

All our studies were performed on a Yonetani-type bovine heart cytochrome $c$ oxidase preparation [16], which has slow electron transfer to the binuclear centre as prepared. In this "slow enzyme", turning over in presence of ascorbate and cytochrome $c$ alone, haem $a$ is appreciably more reduced than cytochrome $c$ whereas the $\mathrm{Cu}_{\mathrm{A}}$ remains more oxidized (results not shown). This is consistent with previous studies implying a block between haem $a$ and the binuclear centre. Due to this, and the heterogeneity of the oxidised forms of the enzyme [18], all our steady state studies started from the fully reduced anaerobic enzyme. This form of the enzyme is considered essentially homogenous with regards to its electron transfer capabilities. Kinetic steady states were then initiated following the addition of oxygen or $\mathrm{H}_{2} \mathrm{O}_{2}$ (in the presence of catalase).

The "classical" kinetic profiles described by Smith and Conrad [7] have the concentration of the substrate cytochrome $c$ in great excess over that of the enzyme. However, these conditions are not appropriate for the spectroscopic study of the other redox centres in the enzyme. Figure 2 shows the effect of increasing levels of the reductant TMPD on the aerobic steady state reduction of cytochrome $c$ in the ratio 1.5 cytochrome $c$ per $a a_{3}$. The plot of fractional reduction vs. [TMPD] is a rectangular hyperbola. In a steady state, the rate of oxygen consumption must be equal to the product $k^{*}[\mathrm{TMPD}]^{*}\left[\mathrm{c}^{3+}\right]$, where $k$ is the second order rate constant for cytochrome $c$ reduction by TMPD. A hyperbolic plot of [TMPD] versus turnover therefore implies that the overall rate is directly proportional to $\left[\mathrm{c}^{2+}\right]$. This was confirmed by directly plotting the cytochrome $c$ redox state versus enzyme turnover (Fig. 2 inset). Therefore the enzyme obeys Smith-Conrad kinetics even when cytochrome $c$ is not in great excess.

Is this consistent with the behaviour of the other spectroscopically-detectable components in the system (cf. Fig. 1)? Figure 3 shows typical behaviour for both cytochrome $c$ and oxidase obtained in such a steady state. After the initial anaerobiosis sequential additions of $\mathrm{H}_{2} \mathrm{O}_{2}$ were made to restore the aerobic steady state. Increasing [TMPD] levels (Fig. 3A) give rise to increases in cyt $c$, haem $a$ and $\mathrm{Cu}_{\mathrm{A}}$ reduction as well as shorter anaerobiosis times whereas varying peroxide (and hence oxygen) only changes anaerobiosis times (Fig. 3B). Of the two varying substrates only ferrocytochrome $c$, and not oxygen, is a controlling factor in these in vitro studies.

Are there additional species present in the steady state? To determine this we first removed the spectral contributions due to known species. Cytochrome $c$ reduction dominates the steady state spectrum at $550 \mathrm{~nm}$. We can therefore readily remove the cytochrome $c$ contribution from the whole steady state spectrum by using the $550-540 \mathrm{~nm}$ difference to determine the correct proportion to remove. The haem $a$ contribution is more complicated to deconvolute. There is no isolated cytochrome $a$ spectrum available. However, the initial reduction of the slow enzyme in the absence of cytochrome $c$ by ascorbate + TMPD involves only haem $a$ and a small amount of $\mathrm{Cu}_{\mathrm{A}}$ with almost no change at the binuclear centre. Noting that the contribution from $\mathrm{Cu}_{\mathrm{A}}$ to the spectra below $700 \mathrm{~nm}$ is insignificant, we therefore used this initial reduction spectrum as the contribution from cytochrome $a$, using the $605-630 \mathrm{~nm}$ absorbance to determine the proportions required.

Figure 4 shows the results. The original steady state difference spectrum is seen in $4 \mathrm{a}$. After subtraction of the cytochrome $c$ reduced minus oxidised spectrum we obtain the set in $4 \mathrm{~b}$. After further subtraction of haem $a$, we obtain the set in $4 \mathrm{c}$. The resulting spectra can then be examined for haem-dependent components other than ferric and ferrous haem $a$. We were particularly interested in species $\mathrm{P}$ and $\mathrm{F}$ (see Fig. 1), which can be formed during the reactions of fully or partially reduced enzyme with oxygen or peroxide. However, under these turnover conditions (approximately $50 \%$ of maximal turnover) we see no spectral evidence for a significant population of the $\mathrm{P}(607 \mathrm{~nm})$ and $\mathrm{F}(580 \mathrm{~nm})$ intermediates. However, the steady state does involves a component generated during turnover with a broad band centred at approximately $598 \mathrm{~nm}$ region and a differential Soret peak-trough (433-414 nm difference) indicating a 'high' to 'low' spin type of transition relative to the slow enzyme. It is clearly different from known low spin species such as the enzyme cyanide complex $[19,20]$, though has some features in common with "fast" forms of the oxidised enzyme [18] (Table 2). 
Using these subtraction techniques, we were never able to detect species we could reliably assign to $\mathrm{P}$ or $\mathrm{F}$ following oxygen-initiated steady states. Nevertheless there are published kinetic models [21] implying a significant population of these species during steady state turnover and their spectral features are not necessarily easy to distinguish from those of haem $a$ and $a_{3}$; this is most notable for the $607 \mathrm{~nm}$ ' $\mathrm{P}$ ' species and the $605 \mathrm{~nm}$ reduced haem $a$ species, especially given that the latter peak position can change under some conditions [22]. Therefore we performed two other experiments to determine if we were missing significant fractions of these oxygen intermediates during turnover.

Firstly we showed that we could indeed detect low levels of $\mathrm{P}$ and $\mathrm{F}$ intermediates in our experiments if we created artificial conditions that favoured their formation. Figure 5 shows that some compound $\mathrm{P}$ and $\mathrm{F}$ forms can be observed immediately after peroxide addition in the presence of lower levels of catalase. Ferric oxidase competes for peroxide at low catalase levels and therefore these higher oxidation state forms can be seen immediately after peroxide addition. But they are not stable steady state forms. They both disappear as the steady state turnover continues, species $\mathrm{P}$ persisting for a few seconds and species $\mathrm{F}$ for a little longer, until the same steady state as secured by oxygen is restored. The data in Figure 5 gives us confidence that were $\mathrm{P}$ and $\mathrm{F}$ to be significantly populated intermediates in the aerobic steady state we would be able to detect them.

Secondly we normalised the spectral changes at different levels of turnover to identical values at 605 minus $630 \mathrm{~nm}$ (Supplementary Figure 1). The spectra overlay over a very wide range of enzyme turnovers, and hence haem a reduction, strongly suggesting that variations in the fraction of species $\mathrm{P}$ do not contribute to the steady state spectral changes in this region.

Based on the ideas of Moody [23], Giuffre et al. [21, 24] have proposed that at slow turnover there will be equipopulation of the O, E, P and F species (Figure 1) because each step is limited by a similar slow electron entry rate. This is inconsistent with our findings. If however the electron entry rate is determined by a product of an intrinsic rate constant and the concentration of the quasi-equilibrium redox complex $a / \mathrm{Cu}_{\mathrm{A}}$ the steady state concentrations will be proportional to the reciprocals of the relevant rate constants. When the partial reactions are examined the $\mathrm{P} \Rightarrow \mathrm{F}$ and $\mathrm{F} \Rightarrow \mathrm{O}$ rates are reportedly of the order of $10,000 \mathrm{~s}^{-1}[25,26]$ whereas the $\mathrm{O} \Rightarrow \mathrm{E}$ and $\mathrm{E} \Rightarrow \mathrm{R}$ rates are much slower (circa 1,000 s$~^{-1}$ ) [27, 28]. The maximal levels of $\mathrm{P}$ and $\mathrm{F}$ will therefore be no more than $10 \%$ those of $\mathrm{E}$ and $\mathrm{O}$ and therefore undetectable with the present methodology. Again the measured partial rate constants are consistent with our measured detectable steady state intermediates. The relative levels of $\mathrm{E} \& \mathrm{O}$ remain uncertain but as the $\mathrm{E}$ state involves almost exclusive reduction of $\mathrm{Cu}_{\mathrm{B}}$ [29] and not haem $a_{3}$ its spectral characteristics will be almost identical to those of ' $O$ ' and again undetectable in the visible and Soret regions.

A readily detectable spectral species in oxidised cytochrome oxidase is the "655nm band" [30]. At even longer wavelengths the near infrared (NIR) signature of $\mathrm{Cu}_{\mathrm{A}}$ can be detected [31, 32]. In order to study spectral features in the $620-950 \mathrm{~nm}$ region, we examined the redox changes at higher enzyme levels and over a more extended wavelength range. Figure 6 shows the results. Clear bleaching of the "655 nm band" and a broad NIR $830 \mathrm{~nm}$ feature accompany changes in cytochrome $c$ at $550 \mathrm{~nm}$ and haem $a$ at $605 \mathrm{~nm}$. In previous studies we were unable to detect significant changes at $830 \mathrm{~nm}$ during uninhibited enzyme turnover [32]; we now attribute this to the lower turnover rates used. As well as $\mathrm{Cu}_{\mathrm{A}}$, intermediates $\mathrm{P}$ and $\mathrm{F}$ [33] and reduced haem $a_{3}$ [34] also have small spectral features in this NIR region. Therefore we were keen to assign the spectral features in the NIR to $\mathrm{Cu}_{\mathrm{A}}$ alone so that we could quantitate the redox state changes observed. Although there are no separate spectral data for mammalian $\mathrm{Cu}_{\mathrm{A}}$, subunit II samples containing $\mathrm{Cu}_{\mathrm{A}}$ have been engineered and expressed from several bacterial enzymes. We compared the difference spectra for Thermus thermophilus $b a_{3}$ subunit II $\mathrm{Cu}_{\mathrm{A}}$ with those in our $a a_{3}$ steady state spectra [35]. The magnitudes of the two difference spectra are almost identical and the shape and positions correspond closely when the bacterial subunit II spectrum is red-shifted by $34 \mathrm{~nm}$. We are therefore confident that the features we see between 750 and $900 \mathrm{~nm}$ in the steady state can be primarily attributed to redox changes in the $\mathrm{Cu}_{\mathrm{A}}$ centre.

We are now finally in a position to examine the redox behaviour of the visible oxidase components as quantitative functions of the steady state reduction of cytochrome $c$. 
Calculated values for the oxidase redox potentials thus depend upon the potential(s) assigned to cytochrome $c$. We used a cytochrome $c$ potential of $+260 \mathrm{mV}$ in our calculations [36]. Figure 7 plots the redox status of haem $a$ as a function of that of cytochrome $c$. The use of high TMPD and peroxide concentrations has meant that, unlike our previous studies [32], we have been able to follow a much wider range of haem $a$ reduction levels. Under these conditions we now no longer see an anomalous apparent saturation of haem $a$ reduction at relatively low levels of cytochrome $c$ reduction. It is clear, however, that haem $a$ is not behaving as a single Nernstian (" $n=1$ ") species. Interpretation of the redox behaviour requires the postulation of at least two forms, a high potential and a low potential one, titrated over distinct redox ranges. It is less easy to be confident about the shape of the curves for the lower extinction coefficient chromophores, due to noise in the data at low reduction levels. However, given the known multiple mutual redox interactions in the enzyme [37-39] and the clear redox interactions in haem $a$ (Figure 7), we feel confident in not forcing $n=1$ fits to the other components. Supplementary Figures 2 and 3 shows the results for $\mathrm{Cu}_{\mathrm{A}}$ and the 655 $\mathrm{nm}$ band. Fitting the data over the full redox range also requires at least two species in each case. In the steady state the apparent redox potentials needed to simulate all the experimental data are listed in Table 3.

How do our experimental results on the steady state redox levels increase our understanding of the factors affecting enzyme turnover? Previous studies have focused on kinetic arguments. Rather surprisingly, given the large literature, there has not been a determined attempt to use the known redox interactions in the enzyme to understand the steady state kinetics. We will now show that such an approach can be very fruitful with regards to the haem $a$ redox state. It has been known since the original redox studies of Minnaert [40] that haem a does not engage in a simple 1electron equilibrium with cytochrome $c$ or with redox-active donor/acceptor systems. Detailed studies were later carried out by Wilson and Dutton [41] for mitochondrial oxidase under varied conditions and in the presence and absence of terminal inhibitors. These data were interpreted by Nicholls \& Petersen [39] in terms of a haem-haem interaction in which the redox potential of each haem was dependent upon the redox state of the other (i.e. the redox potentials showed anticooperative interaction). However, given the fact that in our aerobic experiments haem $a_{3}$ is not significantly reduced, it is unlikely that the haem $a$ / haem $a_{3}$ anti-cooperative interaction is relevant to the steady state. However this is not the only redox interaction in the enzyme. Minnaert showed that haem $a$ had anomalous redox behaviour even in the presence of cyanide where haem $a_{3}$ was held in the ferric low spin $\mathrm{CN}^{-}$ligated state over the whole range of haem $a$ reduction levels [40]. Nicholls \& Wrigglesworth [38] therefore later modified the (so-called neoclassical) interaction model to include the binuclear centre copper $\left(\mathrm{Cu}_{\mathrm{B}}\right)$. Moody and Rich [37] were then able to show that the biphasic anaerobic haem a reduction in the presence of cyanide represented an interaction with both $\mathrm{Cu}_{\mathrm{B}}$ and $\mathrm{Cu}_{\mathrm{A}}$.

So it is clear that under equilibrium conditions there is a wide range of redox interactions between haem $a, \mathrm{Cu}_{\mathrm{A}}$ and $\mathrm{Cu}_{\mathrm{B}}$. This now provides an explanation for the behaviour of haem $a$ in the catalytic steady state. The first electron to haem $a$ from $\mathrm{Cu}_{\mathrm{A}}$ can also be shared with $\mathrm{Cu}_{\mathrm{B}}$; the second electron (giving rise to a system with both haem $a$ and $\mathrm{Cu}_{\mathrm{B}}$ reduced) is then added at an average potential about $60-80 \mathrm{mV}$ lower than the first one.

We now have an explanation based on quasi-equilibrium conditions between the sequence of electron carriers $\left(c \Leftrightarrow \mathrm{Cu}_{\mathrm{A}} \Leftrightarrow\right.$ haem $\left.a\right)$. But how is this consistent with Smith-Conrad kinetics? That is, how can the turnover remain proportional to the fractional reduction of cytochrome $c$, the component furthest from the first quasi-irreversible step? This is only possible if the final potential in the equilibrium sequence is close to that of cytochrome $c$ when the system will behave 'as if' the oxidation of the cytochrome $c$ were the rate-determining step. Indeed inspection of Figure 7 shows that in the purified enzyme the cytochrome $c$ and haem $a$ 'steady state' redox potentials are indeed closely matched. The oxidase under physiologically plausible $c$ : $a a_{3}$ enzyme ratios still obeys apparent "Smith-Conrad" kinetics but this must now be explained as a consequence of the redox states of haem $a$ and $\mathrm{Cu}_{\mathrm{A}}$ tracking that of cytochrome $c$ and not due to rate-limiting electron transfer from bound cytochrome $c$ to enzyme. 
Therefore an important conclusion from this part of the work is that Smith-Conrad kinetics is not an absolute function of the enzyme system, but a coincidence of redox interactions. Under conditions where the $c / a$ quasi-equilibrium is altered, flux may no longer be a linear function of the ferrocytochrome $c$ concentration. The presence of a proton motive force between cytochrome $c$ and haem $a$ will alter their relative potentials [42]. Indeed in coupled mitochondria [43] flux maps closer to reduced haem $a$ than reduced cytochrome $c$.

The behaviour of the " $655 \mathrm{~nm}$ band" in these studies is intriguing, although caution is required given that the exact physical identity of the species causing this spectral feature is unclear $[30,44]$. The band is present in all forms of the fully oxidised enzyme when haem $a_{3}$ is high spin e.g. formate bound. It is lost in the $\mathrm{P}$ and $\mathrm{F}$ intermediates and in low spin forms of the enzyme e.g. cyanide bound [45]. It is seen in slow preparations of the enzyme where haem $a_{3}$ is high spin. Reduction of $\mathrm{Cu}_{\mathrm{B}}$ in redox titrations bleaches the band, leading to suggestions that it is present in enzyme species where haem $a_{3}$ is high spin and $\mathrm{Cu}_{\mathrm{B}}$ is oxidised [30]. However, it is still seen, albeit slightly blue-shifted, in forms of the "fast enzyme" $[18,30]$ and in our steady state spectral species where, at least according to the Soret band, the enzyme has undergone a partial high-to-low spin transition from the slow form.

We have clearly shown that changes in levels of $P$ or $F$ intermediates cannot account for the $655 \mathrm{~nm}$ bleaching. There is no evidence of large haem $a_{3}$ reduction or spin state changes between slow and fast turnovers. It is clear that haem $a_{3}$ remains mostly oxidised with only small spin state changes if any during turnover. By a process of elimination we suggest the $655 \mathrm{~nm}$ band is therefore tracking the reduction of the otherwise optically silent $\mathrm{Cu}_{\mathrm{B}}$ species. Under anaerobic conditions the $655 \mathrm{~nm}$ band titrates at $400 \mathrm{mV}$ [30] in the unliganded enzyme, close to that of $\mathrm{Cu}_{\mathrm{B}}$ [46]. However, in the presence of formate it titrates at $210 \mathrm{mV}$, much closer to the low potential value seen in our steady state conditions. We therefore tentatively assign the $655 \mathrm{~nm}$ band to a low potential $\mathrm{Cu}_{\mathrm{B}}$ as part of an electron donor quasi-equilibrium $\left(\mathrm{c} \Leftrightarrow \mathrm{Cu}_{\mathrm{A}} \Leftrightarrow \mathrm{a} \Leftrightarrow \mathrm{Cu}_{\mathrm{B}}\right.$ ).

Can we now simplify the redox interactions into a coherent model of the oxidase steady state? First we exclude haem $a_{3}$ which remains nearly $100 \%$ oxidised under our aerobic conditions. If the remaining three oxidase components are in near equilibrium with cytochrome $c$ and interact with each other we are faced with a system involving 8 species and 12 redox equilibria as shown in Fig. 8. Figure 9 shows the data fitted to such a model. It may be noted that the original fitting allowed three separate parameters for each redox process, a total of 9 parameters for the set. The fits employed in Fig. 9 are linked, and only involve seven independent parameters (in this case redox potentials). Allowing multiple interactions at the same time permits data fitting with a smaller range of postulated potentials than were used for the single fits (the method used in Table 3). The values of the potentials are subject to considerable uncertainties $(+/-20 \mathrm{mV})$. However, the important point is that a relatively simple model of redox interactions is consistent with the data. Although the redox potentials and interactions observed in Figure 8 are broadly within the range of those obtained from static equilibrium measurements [37-39, 41], there is a notable absence of the higher potentials $\left(>300 \mathrm{mV}\right.$ ) for $\mathrm{Cu}_{\mathrm{B}}$ and haem $a$ seen when the purified enzyme is titrated during anaerobic equilibrium experiments. The structure of the binuclear centre during steady state turnover is distinct from that seen in the enzyme when it is not consuming oxygen.

What then are the rate-controlling step(s) at saturating ferrocytochrome $c$ and oxygen concentrations? Kinetic analysis of many of the partial reactions indicates that it is unlikely that there are simple electron transfer limitations. Bound ferrocytochrome $c$ can transfer an electron to $\mathrm{Cu}_{\mathrm{A}}$ [4] with a rate between 50,000 and $100,000 \mathrm{~s}^{-1} . \mathrm{Cu}_{\mathrm{A}}$ and haem $a / \mathrm{Cu}_{\mathrm{B}}$ equilibrate [47] with a rate of $20,000 \mathrm{~s}^{-1}$. The rate of electron exchange between haem $a$ and $\mathrm{Cu}_{\mathrm{B}}$ is uncertain, but in bacterial $a a_{3}$ enzymes it may be about $1,000 \mathrm{~s}^{-1}$ [27]. The rate of reduction of the $a_{3}$ haem is even more uncertain, but is probably of the same order of magnitude as that of $\mathrm{Cu}_{\mathrm{B}}$. On the oxidative side of the reaction scheme the transformations of the oxy complex (A) into compound $\mathrm{P}$ or $\mathrm{F}$ [25] are rapid (10,000-25,000 s-1). Reduction of species $\mathrm{F}$ to give the oxidized $(\mathrm{O})$ state [26] is also relatively rapid $\left(10,000 \mathrm{~s}^{-1}\right)$. If the reaction with oxygen $(\mathrm{R} \Rightarrow \mathrm{A} \Rightarrow \mathrm{P})$ and the reduction of $\mathrm{P} \Rightarrow \mathrm{F}$ and $\mathrm{F} \Rightarrow \mathrm{O}$ are rapid the slow steps must be on the reductive side of the cycle. Under our conditions (below the $\mathrm{K}_{\mathrm{m}}$ for cytochrome $c$ ) at least part of the turnover limitation will be from the rate of 
cytochrome $c$ binding to the oxidase. Beyond this our studies here show that the internal oxidase turnover at full reduction of cytochrome $c$ is not limited by electron abstraction from bound cytochrome $c$ but by electron transfer to the binuclear centre, the reduction of either or both $\mathrm{Cu}_{\mathrm{B}}$ or haem $a_{3}$. Although the electron interchange between haem $a$ and haem $a_{3}$ in the mixed valence enzyme is extremely rapid [48] this cannot be the relevant reaction in the usual steady state. The maximal turnover in our system is of the order of $100-150 \mathrm{~s}^{-1}$; this requires three limiting processes with rates of the order of $400 \mathrm{~s}^{-1}$ or two processes with rates of the order of $250 \mathrm{~s}^{-1}$. The reductions of $\mathrm{O}$ to $\mathrm{E}$ and of $\mathrm{E}$ to $\mathrm{R}$ may provide two such processes. Each of these steps is expected to involve a protonation, either addition of a proton to a deprotonated protein group or neutralisation of a hydroxyl ion present in species ' $\mathrm{O}$ '. This must reduce the rates from the nano or pico second to the millisecond time region. Modelling the resulting steady state involves mostly $\mathrm{O}$, a little $\mathrm{E}$, and negligible amounts of R, P \& F (results not shown). These reactions are much slower than the analogous partial reactions and must therefore involve secondary 'invisible' steps including protonation/deprotonation and possibly conformational changes.

To summarise we have developed for the first time a model that is consistent with the known steady state enzyme kinetics, partial reaction rates and redox interactions of this key multi-substrate membrane-bound enzyme. These studies have implications beyond an understanding of the basic enzyme mechanism. Cytochrome oxidase redox states are frequently used as markers of cellular energy state in vitro and in vivo [10]. In particular the $\mathrm{Cu}_{\mathrm{A}}$ centre is used in Near Infrared Spectroscopy (NIRS) to study brain and muscle function in health and disease [15]. Tissue changes are frequently interpreted only in terms of a single substrate (oxygen). This work suggests that at constant oxygen concentration the $\mathrm{Cu}_{\mathrm{A}}$ redox state closely tracks that of cytochrome $c$ and hence, given Smith-Conrad kinetics, the oxygen consumption rate. 


\section{Acknowledgements}

We thank Mike Wilson (University of Essex) for helpful discussions and Julie Double \& Richard Ranson for technical assistance.

\section{Funding}

We thank the UK Biotechnology and Biological Sciences Research Council (grant (D0609821/1) and Engineering and Physical Sciences Research Council (grant EP/F006551/1) for financial support.

\section{Abbreviations footnote}

${ }^{1}$ TMPD, N,N,N',N',tetramethyl-p-phenylenediamine; lauryl maltoside, n-Dodecyl $\beta$-D-maltoside; $\left[c^{2+}\right]$, concentration of reduced cytochrome $c$; slow enzyme, fully oxidized (ferric/cupric) enzyme with slow ligand binding characteristics; fast enzyme, fully oxidized (ferric/cupric) enzyme with fast ligand binding characteristics; A, fully reduced enzyme binuclear centre with oxygen bound; $\mathrm{P}$, enzyme oxygen intermediate characterised by an absorbance spectrum at $607 \mathrm{~nm}$ relative to the oxidised enzyme; F, enzyme oxygen intermediate characterised by an absorbance spectrum at 580 $\mathrm{nm}$ relative to the oxidised enzyme.

\section{References}

1 Minnaert, K. (1961) The kinetics of cytochrome c oxidase. I. The system: cytochrome ccytochrome oxidase-oxygen. Biochim. Biophys. Acta 50, 23-34

2 Cooper, C. E., Mason, M. G. and Nicholls, P. (2008) A dynamic model of nitric oxide inhibition of mitochondrial cytochrome c oxidase. Biochim. Biophys. Acta 1777, 867-876

3 Zhen, Y., Hoganson, C. W., Babcock, G. T. and Ferguson-Miller, S. (1999) Definition of the interaction domain for cytochrome c on cytochrome c oxidase. I. Biochemical, spectral, and kinetic characterization of surface mutants in subunit II of Rhodobacter sphaeroides cytochrome aa(3). J. Biol. Chem. 274, 38032-38041

4 Wang, K., Geren, L., Zhen, Y., Ma, L., Ferguson-Miller, S., Durham, B. and Millett, F. (2002) Mutants of the CuA site in cytochrome c oxidase of Rhodobacter sphaeroides: II. Rapid kinetic analysis of electron transfer. Biochemistry 41, 2298-2304

5 Brooks, S. P. and Nicholls, P. (1982) Anion and ionic strength effects upon the oxidation of cytochrome c by cytochrome c oxidase. Biochim Biophys Acta 680, 33-43

6 Babcock, G. T. and Wikström, M. (1992) Oxygen Activation and the conservation of energy in cell respiration. Nature 356, 301-309

7 Conrad, H. and Smith, L. (1956) A study of the kinetics of the oxidation of cytochrome c by cytochrome c oxidase. Arch. Biochem. Biophys. 63, 403-413

8 Yonetani, T. (1962) Studies on cytochrome oxidase. IV. The cytochrome oxidase activity. J Biol Chem 237, 550-559

9 Gnaiger, E., Steinlechner-Maran, R., Mendez, G., Eberl, T. and Margreiter, R. (1995) Control of mitochondrial and cellular respiration by oxygen. J. Bioenerg. Biomembr. 27, 583-596

10 LaManna, J. C. (2003) The redox state of cytochrome oxidase in brain in vivo: an historical perspective. Adv. Exp. Med. Biol. 530, 535-546

11 Chance, B. (1965) Reaction of oxygen with the respiratory chain in cells and tissues. J. Gen. Physiol. 49, Suppl:163-195

12 Nicholls, P. (1993) The steady state behaviour of cytochrome c oxidase in proteoliposomes. FEBS Lett. 327, 194-198 
13 Beard, D. A. (2005) A biophysical model of the mitochondrial respiratory system and oxidative phosphorylation. PLoS Comput. Biol. 1, e36

14 Korzeniewski, B. and Zoladz, J. A. (2001) A model of oxidative phosphorylation in mammalian skeletal muscle. Biophys. Chem. 92, 17-34

15 Banaji, M., Mallet, A., Elwell, C. E., Nicholls, P. and Cooper, C. E. (2008) A model of brain circulation and metabolism:NIRS signal changes during physiological challenges. PLoS Comput. Biol. 4, e1000212.

16 Yonetani, T. (1960) Studies on cytochrome oxidase. I. Absolute and difference absorption spectra. J Biol Chem 235, 845-852

17 Fylstra, D., Lasdon, L., Watson, J. and Waren, A. (1998) Design and use of the Microsoft Excel Solver. Interfaces 28, 29-55

18 Moody, A. J. (1996) 'As prepared' forms of fully oxidised haem/Cu teminal oxidases. Biochim. Biophys. Acta 1276, 6-20

19 Wikström, M. and Morgan, J. E. (1992) The dioxygen cycle. Spectral, kinetic, and thermodynamic characteristics of ferryl and peroxy intermediates observed by reversal of the cytochrome oxidase reaction. J. Biol. Chem. 267, 10266-10273

20 Wrigglesworth, J. M. (1984) Formation and reduction of a 'peroxy' intermediate of cytochrome c oxidase by hydrogen peroxide. Biochem. J. 217, 715-719

21 Giuffre, A., Barone, M. C., Mastronicola, D., D'Itri, E., Sarti, P. and Brunori, M. (2000) Reaction of nitric oxide with the turnover intermediates of cytochrome $\mathrm{c}$ oxidase: reaction pathway and functional effects. Biochemistry 39, 15446-15453.

22 Saari, H., Penttila, T. and Wikstrom, M. (1980) Interactions of Ca2+ and H+ with heme A in cytochrome oxidase. J. Bioenerg. Biomembr. 12, 325-338

23 Moody, A. J. (1991) Ligation and electronation states of cytochrome-c oxidase in relation to other oxidases and peroxidases. Biochem. Soc. Trans. 19, 617-622

24 Brunori, M., Giuffre, A. and Sarti, P. (2005) Cytochrome c oxidase, ligands and electrons. J. Inorg. Biochem. 99, 324-336

25 Hill, B. C. (1991) The reaction of the Electrostatic Cytochrome $c$-Cytochrome Oxidase Complex with Oxygen. J. Biol. Chem. 266, 2219-2226

26 Zaslavsky, D., Sadoski, R. C., Wang, K., Durham, B., Gennis, R. B. and Millett, F. (1998) Single electron reduction of cytochrome c oxidase compound F: resolution of partial steps by transient spectroscopy. Biochemistry 37, 14910-14916

27 Belevich, I., Bloch, D. A., Belevich, N., Wikstrom, M. and Verkhovsky, M. I. (2007) Exploring the proton pump mechanism of cytochrome c oxidase in real time. Proc. Natl. Acad. Sci. U S A 104, 2685-2690

28 Brand, S. E., Rajagukguk, S., Ganesan, K., Geren, L., Fabian, M., Han, D., Gennis, R. B., Durham, B. and Millett, F. (2007) A new ruthenium complex to study single-electron reduction of the pulsed $\mathrm{O}(\mathrm{H})$ state of detergent-solubilized cytochrome oxidase. Biochemistry 46, 14610-14618

29 Jancura, D., Antalik, M., Berka, V., Palmer, G. and Fabian, M. (2006) Filling the catalytic site of cytochrome c oxidase with electrons. Reduced $\mathrm{CuB}$ facilitates internal electron transfer to heme a3. J. Biol Chem. 281, 20003-20010

30 Mitchell, R., Mitchell, P. and Rich, P. R. (1991) The assignment of the $655 \mathrm{~nm}$ spectral band of cytochrome oxidase [published erratum appears in FEBS Lett 1991 May 6;282(2):449]. FEBS Lett. 280, 321-324

31 Wharton, D. C. and Tzagoloff, A. (1964) Studies on the electron transfer system. LVII. The near infrared absorption band of cytochrome oxidase. J. Biol. Chem. 239, 2036-2040

32 Nicholls, P. and Chanady, G. A. (1982) Titration and steady state behaviour of the 830nm chromophore in cytochrome $c$ oxidase. Biochem. J. 203, 541-549

33 Thörnström, P.-E., Brzezinski, P., Fredriksson, P.-O. and Malmström, B. G. (1988) Cytochrome $c$ Oxidase as an Electron-Transort-Driven Proton Pump: $\mathrm{pH}$ Dependence of the Reduction Levels of the Redox Centres during Turnover. Biochemistry 27, 5441-5447 
34 Ingledew, W. J., Bacon, M. and Rich, P. R. (1992) Characterisation of a near infra-red absorption band of the Eschericia coli quinol oxidase, cytochrome $o$, which is attributable to the high-spin ferrous haem of the binuclear site. FEBS Lett. 305, 167-170

35 Slutter, C. E., Sanders, D., Wittung, P., Malmstrom, B. G., Aasa, R., Richards, J. H., Gray, H. B. and Fee, J. A. (1996) Water-soluble, recombinant CuA-domain of the cytochrome ba3 subunit II from Thermus thermophilus. Biochemistry 35, 3387-3395

36 Blair, D. F., Ellis, W. R., Jr., Wang, H., Gray, H. B. and Chan, S. I. (1986) Spectroelectrochemical study of cytochrome c oxidase: $\mathrm{pH}$ and temperature dependences of the cytochrome potentials. Characterization of site-site interactions. J. Biol. Chem. 261, 11524-11537

37 Moody, A. J. and Rich, P. R. (1990) The effect of $\mathrm{pH}$ on redox titrations of haem a in cyanide-liganded cytochrome-c oxidase: experimental and modelling studies. Biochim. Biophys. Acta 1015, 205-215

38 Nicholls, P. and Wrigglesworth, J. M. (1988) Routes of cytochrome a3 reduction. The neoclassical model revisited. Ann. N.Y. Acad. Sci. 550, 59-67

39 Nicholls, P. and Petersen, L. C. (1974) Haem-haem interactions in cytochrome aa3 during the anaerobic-aerobic transition. Biochim. Biophys. Acta 357, 462-467

40 Minnaert, K. (1965) Measurement of the equilibrium constant of the reaction between cytochrome c and cytochrome a. Biochim. Biophys. Acta 110, 42-56

41 Wilson, D. F. and Dutton, P. L. (1970) The oxidation-reduction potentials of cytochromes a and $\mathrm{a} 3$ in intact rat liver mitochondria. Arch. Biochem. Biophys. 136, 583-585

42 Hinkle, P. and Mitchell, P. (1970) Effect of membrane potential on equilibrium poise between cytochrome $a$ and cytochrome $c$ in rat liver mitochondria. Bioenergetics 1, 45-60

43 Morgan, J. E. and Wikström, M. (1991) Steady-State Redox Behavior of Cytochrome c, Cytochrome a, and CuA of Cytochrome c Oxidase in Intact Rat Liver Mitochondria. Biochemistry 30, 948-958

44 Hartzell, C. R. and Beinert, H. (1976) Oxido-reductive titrations of cytochrome c oxidase followed by EPR spectroscopy. Biochim. Biophys. Acta 423, 323-338

45 Wrigglesworth, J. M., Ioannidis, N. and Nicholls, P. (1988) Spectrophotometric characterization of intermediate redox states of cytochrome oxidase. Ann. N.Y. Acad. Sci. 550, 150-160

46 Schroedl, N. A. and Hartzell, C. R. (1977) Oxidative titrations of reduced cytochrome aa3: correlation of midpoint potentials and extinction coefficients observed at three major absorption bands. Biochemistry 16, 4961-4965

47 Farver, O., Einarsdottir, O. and Pecht, I. (2000) Electron transfer rates and equilibrium within cytochrome c oxidase. Eur. J. Biochem. 267, 950-954

48 Pilet, E., Jasaitis, A., Lieb1, U. and Vos, M. H. (2004) Electron transfer between hemes in mammalian cytochrome c oxidase. Proc. Natl. Acad. Sci. U S A 101, 16198-16203

49 Liao, G. L. and Palmer, G. (1996) The reduced minus oxidized difference spectra of cytochromes a and a3. Biochim. Biophys. Acta 1274, 109-111

50 Fabian, M. and Palmer, G. (1995) The interaction of cytochrome oxidase with hydrogen peroxide: the relationship of compounds P and F. Biochemistry 34, 13802-13810 


\section{Tables and Figures}

$\begin{array}{ccc}\text { Redox centre } & \text { Wavelengths monitored }(\mathbf{n m}) & \mathbf{c y t} \boldsymbol{c} \boldsymbol{\varepsilon} \text { red- ox } \mathbf{M}^{\mathbf{- 1}} \mathbf{c m}^{-\mathbf{1}} \\ \text { Cytochrome } c & 550-540 & \text { NA } \\ \text { Haem a } & 605-630 & -337 \\ \text { "655 nm band" } & 650-0.5^{*}(620+680) & 37 \\ \mathrm{Cu}_{\mathrm{A}} & 825-0.5^{*}(750+900) & 127\end{array}$

Table 1 Wavelengths and algorithms used to measure redox state changes Correction for cytochrome $c$ changes indicated in right hand column.

Tables

\begin{tabular}{||l|l|l|l||}
\hline Spectral complex & $\begin{array}{l}\text { Soret } \\
\text { maximum }\end{array}$ & $\begin{array}{l}\text { Soret } \\
\text { minimum }\end{array}$ & $\begin{array}{l}\text { Visibie } \\
\text { maximum }\end{array}$ \\
\hline Cyanide bound [45] & 434 & 413 & 587 \\
\hline haem $\boldsymbol{a}_{3}$ reduced [49] & 444 & 414 & $\begin{array}{l}600 \text { (broad) } \\
585 \text { (shoulder) }\end{array}$ \\
\hline ' $\mathbf{F}$ ' intermediate [50] & 436 & 413 & 578 \\
\hline 'P' intermediate [50] & 438 & 414 & 607 \\
\hline Enzyme in turnover (this paper) & 433 & 414 & 598 (broad) \\
\hline
\end{tabular}

Table 2 Spectral features of haem $a_{3}$

All spectral features are differences relative to the oxidized enzyme. Maxima and minima refer to peaks and troughs respectively, in this difference spectrum.

\begin{tabular}{||l|l|l|l||}
\hline & Haem $\boldsymbol{a}$ & $\mathbf{C u}_{\mathrm{A}}$ & $\mathbf{6 5 5} \mathbf{n m}$ band \\
\hline $\mathbf{E}_{\mathbf{0}} \mathbf{1}^{\mathbf{1}}(\mathbf{\%})$ & $239 \pm 5 \mathrm{mV}(46 \%)$ & $193 \pm 6 \mathrm{mV}(60 \%)$ & $218 \pm 5 \mathrm{mV}(63 \%)$ \\
\hline $\mathbf{E}_{\mathbf{0}}{ }^{\prime 2}(\%)$ & $291 \pm 6 \mathrm{mV}(54 \%)$ & $270 \pm 6 \mathrm{mV}(40 \%)$ & $291 \pm 5 \mathrm{mV}(37 \%)$ \\
\hline
\end{tabular}

Table 3 Two-component interacting potentials of cytochrome $c$ oxidase metal centres. Values are versus standard hydrogen electrode. Errors are \pm SEM of the non linear regression fit to the data sets.

Licenced copy. Copying is not permitted, except with prior permission and as allowed by law. 


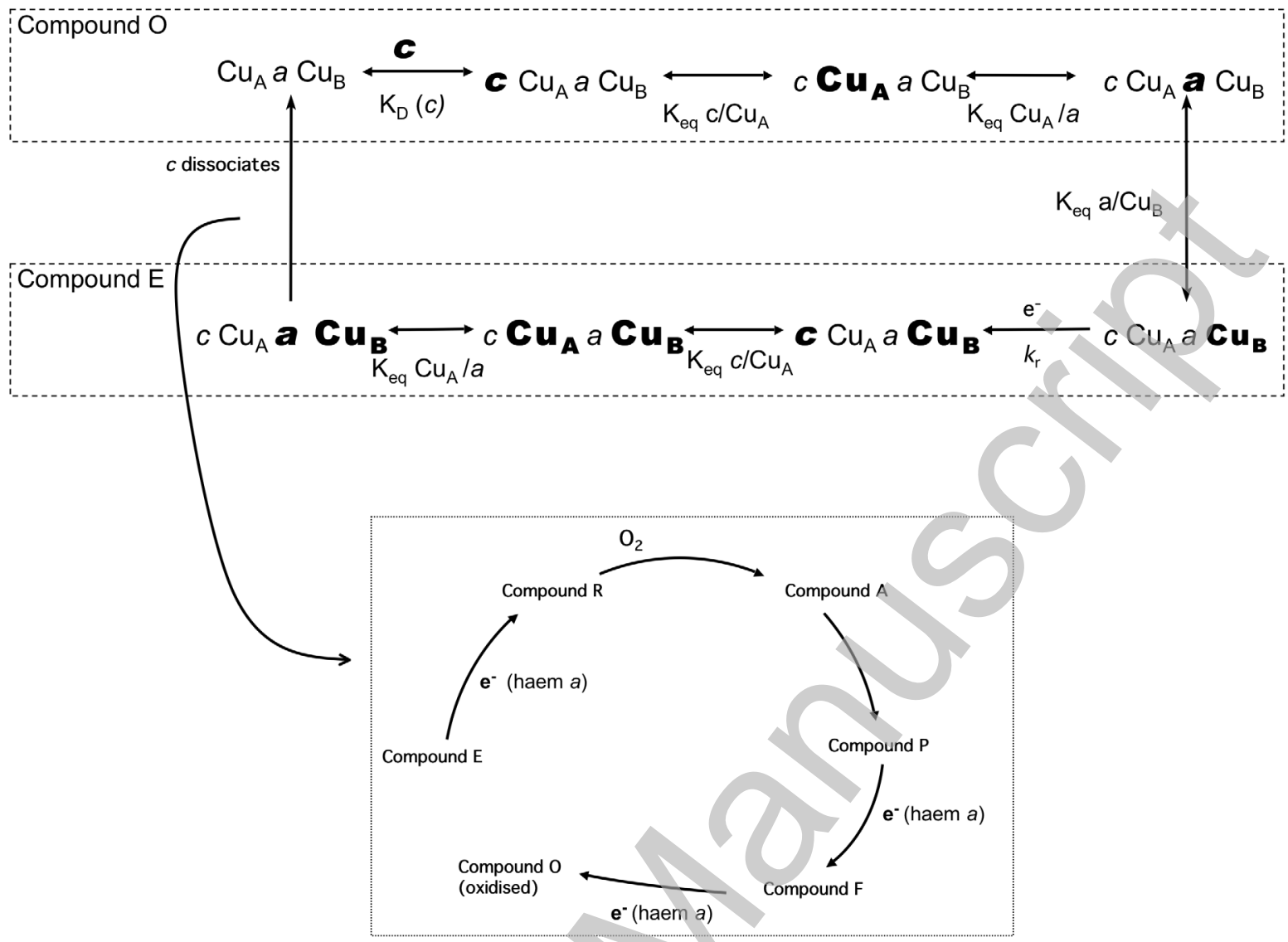

Figure 1 Model of cytochrome $c$ oxidase activity

Summary mechanism for cytochrome $c$ oxidase activity indicating the possible near equilibrium steps. Reduced redox centres are in bold text. The top part of the diagram indicates electron transfer from cytochrome $c$ when the binuclear centre is fully oxidised $(\mathrm{O})$ or is reduced by one electron $(\mathrm{E})$. Following the addition of a second electron into the binuclear centre (R) oxygen can bind and the oxygen reduction chemistry occurs (bottom diagram) regenerating $\mathrm{O}$. Compounds $\mathrm{A}, \mathrm{P}$ and $\mathrm{F}$ are defined solely by their relative redox states here and no attempt is made to comment on the structural details of the intermediates. As illustrated $k_{r}$ is the rate constant for a step involving the reduction of enzyme-bound cytochrome $c$, although the bottom cycle and the top cycles are not intended to operate independently; cytochrome $c$ association and dissociation and electron entry to $\mathrm{Cu}_{\mathrm{A}}$ and haem $a$ are presumably possible in all the intermediates (E, O, A, P, R and F). A full description listing all possibilities would be too complex to illustrate usefully [21]. 


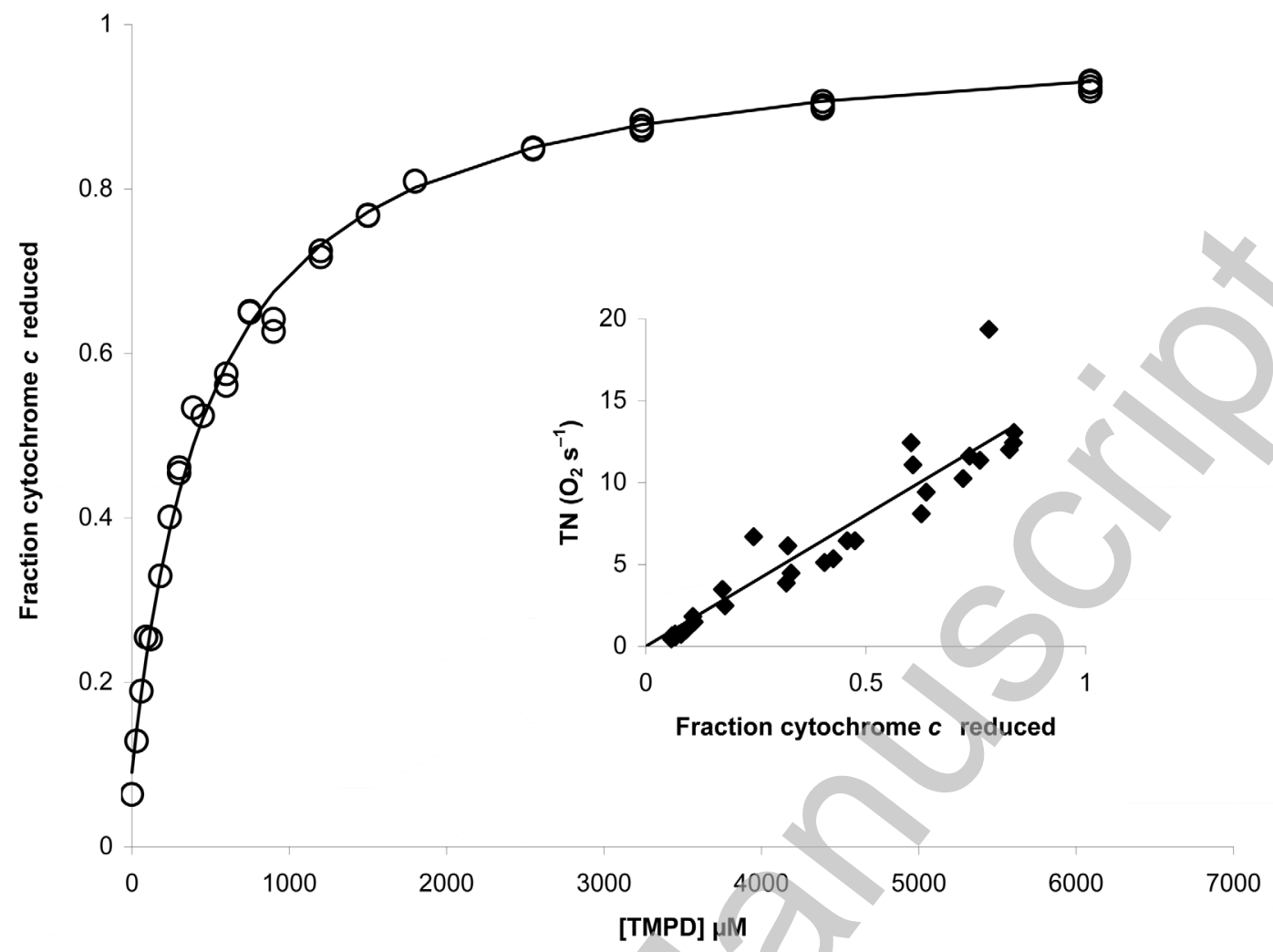

Figure 2 Effect of [TMPD] on the steady state level of fractional reduction of cytochrome $c$.

Ascorbate $(40 \mathrm{mM})$ was present to keep TMPD fully reduced at all concentrations. The data were fitted to a rectangular hyperbola with $V_{\max }$ set to 1.0 (corresponding to maximal reduction of the 10 $\mu \mathrm{M}$ cytochrome $c$ total), $\mathrm{Km}$ fitted to $501( \pm 15.07) \mu \mathrm{M}$ with an apparent offset of $0.091( \pm 0.01)$ equating to the fractional steady state level of reduction of cytochrome $c$ in the presence of ascorbate alone. The inset shows the relationship between fractional cytochrome $c$ reduction and cytochrome $c$ oxidase turnover number. Turnover is calculated from the length of time taken to reach anaerobiosis, as determined spectrally by complete reduction of the cytochromes. 


\section{Figure 3a}

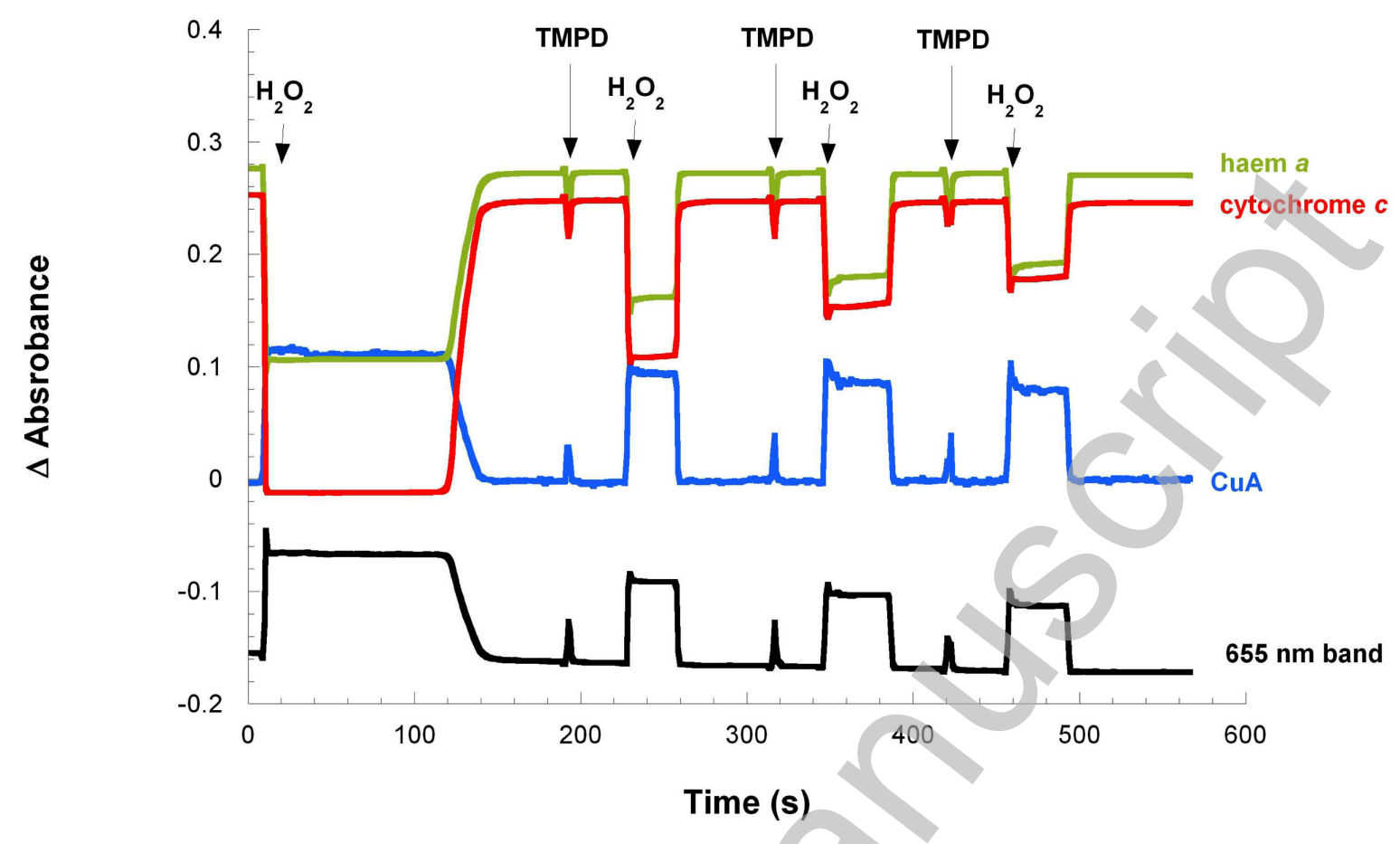

Figure 3b

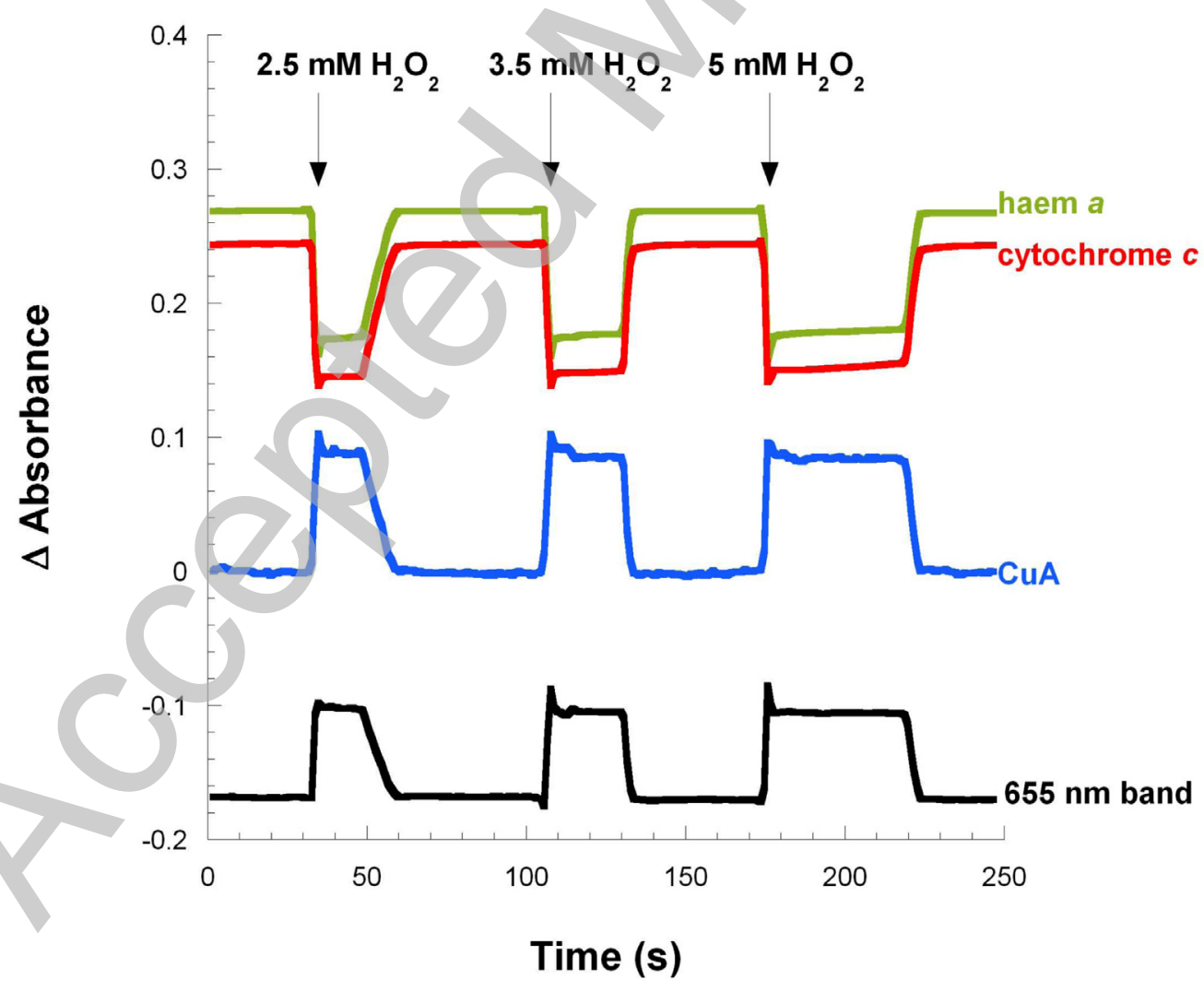

Licenced copy. Copying is not permitted, except with prior permission and as allowed by law. 


\section{Figure 3 Time course of reduction and oxidation of chromophores}

The reduction state of cytochrome $c$ and cytochrome $c$ oxidase redox centres was monitored as follows:

cytochrome $c$ oxidase haem $a: 605-630 \mathrm{~nm}$

- cytochrome $c: 550-540 \mathrm{~nm}$

- cytochrome $c$ oxidase $\mathrm{Cu}_{\mathrm{A}}: 825-0.5 *(750+900) \mathrm{nm}$

—ytochrome $c$ oxidase $655 \mathrm{~nm}$ band : $650-0.5 *(620+680) \mathrm{nm}$

Note that using these wavelengths an increase in reduction results in an increase in absorbance for haem $a$ and cytochrome $c$, but a decreased absorbance for $\mathrm{Cu}_{\mathrm{A}}$ and the $655 \mathrm{~nm}$ band. The sharp changes in reduction indicate depletion of oxygen from the cuvette.

Fig 3A shows the increase in reduction levels with increasing [TMPD]. Traces for $\mathrm{Cu}_{\mathrm{A}}$ and the binuclear centre are scaled up by factors of 30 and 5 respectively. Additions made were $1 \mathrm{mM}$ $\mathrm{H}_{2} \mathrm{O}_{2}, 450 \mu \mathrm{M}$ TMPD, $2.5 \mathrm{mM} \mathrm{H}_{2} \mathrm{O}_{2}, 450 \mu \mathrm{M}$ TMPD, $5 \mathrm{mM} \mathrm{H}_{2} \mathrm{O}_{2}, 450 \mu \mathrm{M}$ TMPD, $5 \mathrm{mM} \mathrm{H}_{2} \mathrm{O}_{2}$ respectively. Catalase was present at $200 \mathrm{nM}$ concentration to immediately convert the added $\mathrm{H}_{2} \mathrm{O}_{2}$ to $\mathrm{O}_{2}$.

Fig 3B shows that the length of the aerobic steady state increases with increasing amounts of peroxide, with negligible change in the level of reduction. Traces for $\mathrm{Cu}_{\mathrm{A}}$ and the binuclear centre are scaled up by factors of 20 and 3 respectively. The TMPD concentration was $900 \mu \mathrm{M}$ throughout. 


\section{Figure 4a}

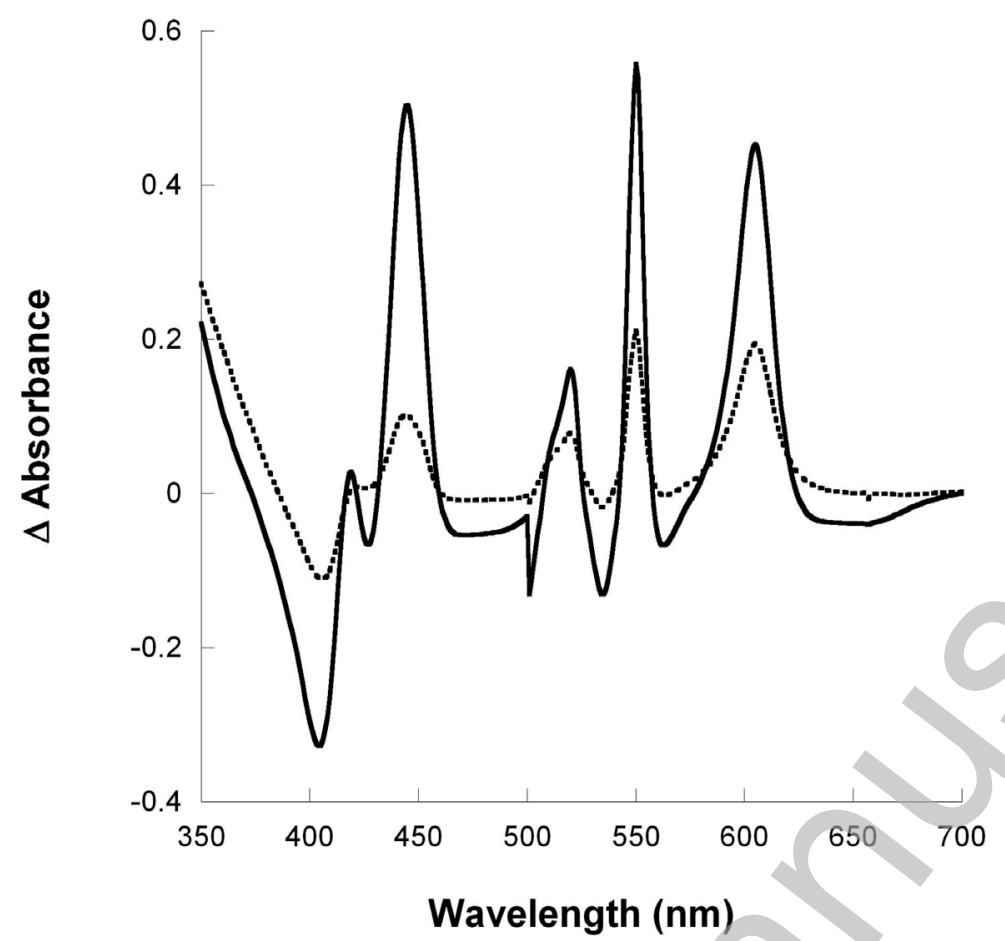

Figure 4b

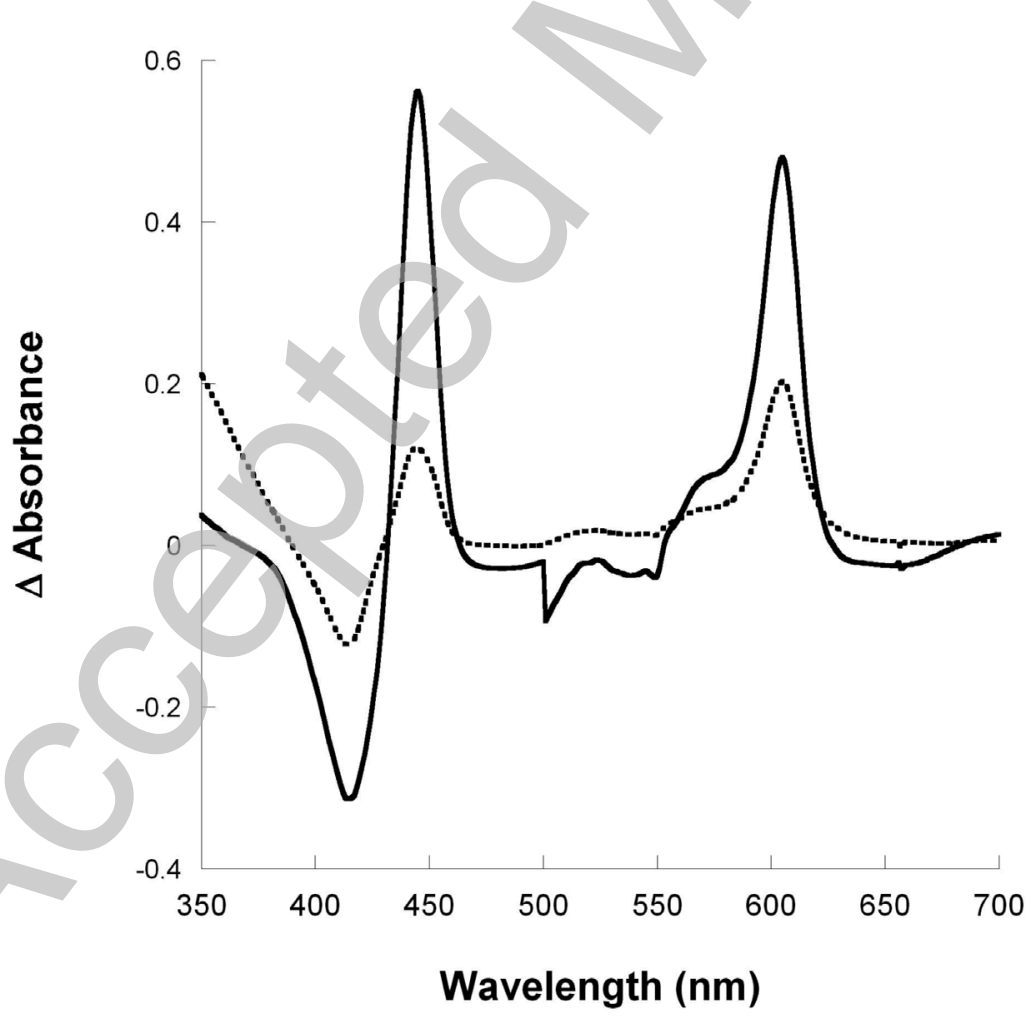




\section{Figure 4c}

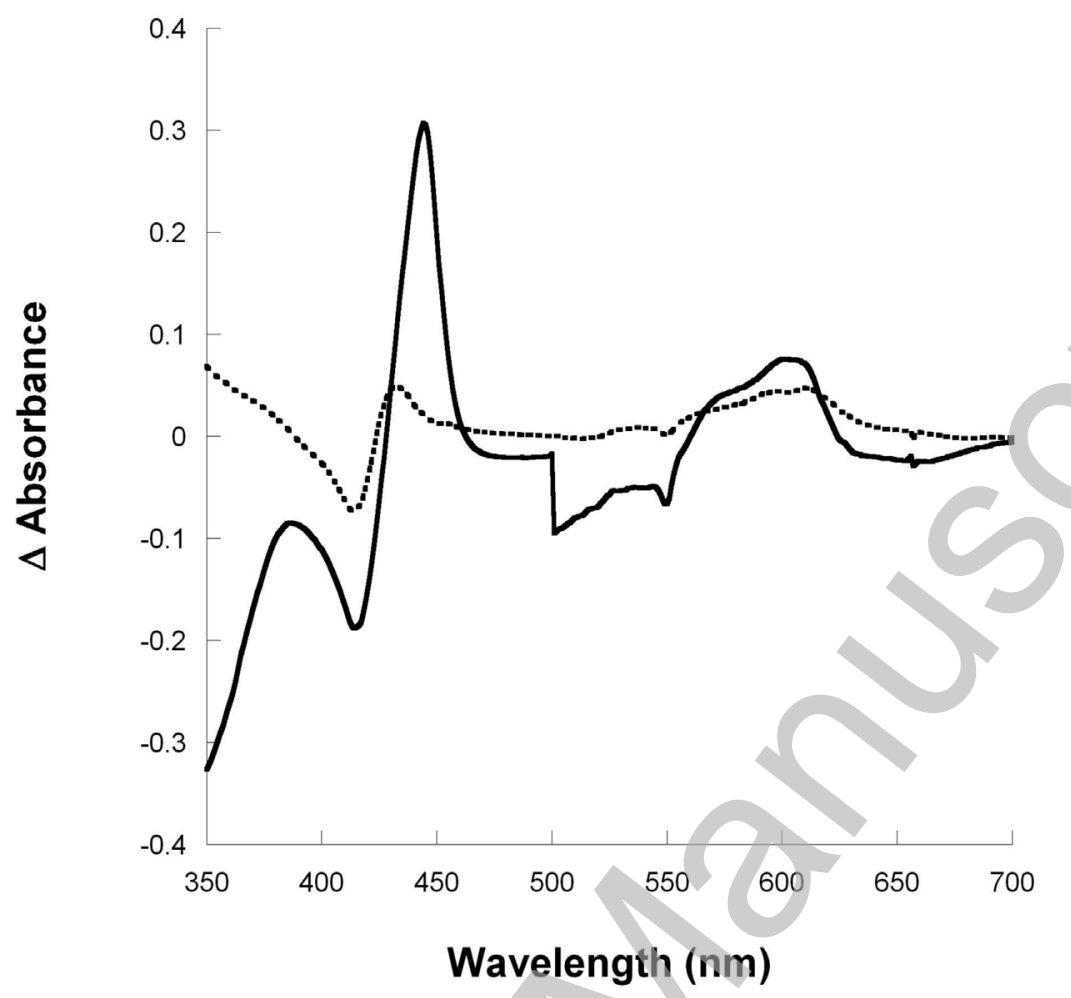

Figure 4 Spectra of cytochrome $c$-cytochrome $c$ oxidase during steady state enzyme turnover

Ascorbate $(7.14 \mathrm{mM})+\mathrm{TMPD}(107 \mu \mathrm{M})$ reduction of $5.8 \mu \mathrm{M}$ cyt. $c$ plus $3.6 \mu \mathrm{M}$ cytochrome $a a_{3}$ in $\mathrm{pH} 7.4,10 \mathrm{mM}$ sodium phosphate buffer, $0.027 \%$ lauryl maltoside. Temp, $30^{\circ} \mathrm{C}$. Spectra in the $500-$ $700 \mathrm{~nm}$ range were expanded times 5 for illustrative purposes.

a: anaerobic minus slow enzyme (black solid lines), steady state minus slow enzyme (black dotted lines)

b: as per A but spectra corrected for the contribution due to reduced minus oxidized cytochrome $c$ c: as per B, but spectra additionally corrected for the contributions due to reduced minus oxidized haem $a$

Licenced copy. Copying is not permitted, except with prior permission and as allowed by law. 

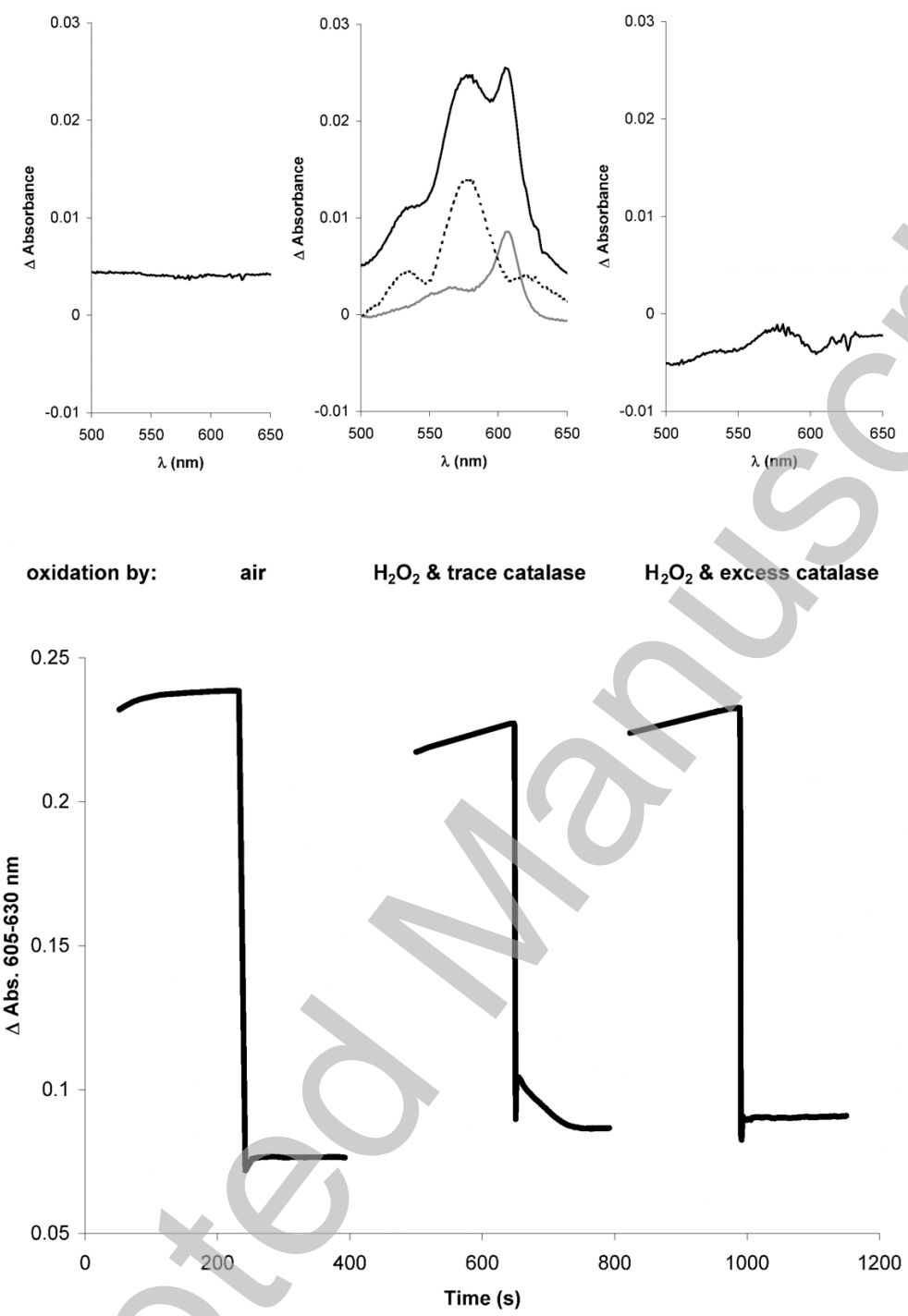

Figure 5 Cytochrome $c$ oxidase oxidation at slow steady state turnover rates

Time traces show oxidation of haem $a(605-630 \mathrm{~nm})$ by addition of air; $\mathrm{H}_{2} \mathrm{O}_{2}$ in the presence of 12.5 $\mathrm{nM}$ catalase; and $\mathrm{H}_{2} \mathrm{O}_{2}$ in the presence of $138 \mathrm{nM}$ catalase. Oxidation by air was effected by drawing up a syringe $(20 \mathrm{ml})$ of ambient air, and carefully bubbling the contents into the cuvette. The difference spectrum above each time trace corresponds to the spectrum a few seconds after addition of oxidant (5-10s) relative to the previous aerobic steady state spectrum (which was recorded after a cycle of reduction and re-oxidation.). No discernible optical features are seen in the initial air-induced spectrum (left). In contrast, in the presence of $\mathrm{H}_{2} \mathrm{O}_{2}$ and trace catalase (centre) the black spectrum (initial difference) shows clear spectral contributions from ' $\mathrm{P}$ ' (25\% of total oxidase, $607 \mathrm{~nm}$ peak, grey spectrum) and ' $\mathrm{F}$ ' (30\% of total oxidase, $578 \mathrm{~nm}$ peak, black dotted spectrum). These species decay with time resulting in a steady state spectrum indistinguishable from that induced by air. Oxidation with $\mathrm{H}_{2} \mathrm{O}_{2}$ at high catalase (right) completely abolishes formation of 'P', with only a residual amount of ' $\mathrm{F}$ ' remaining that subsequently decays. 

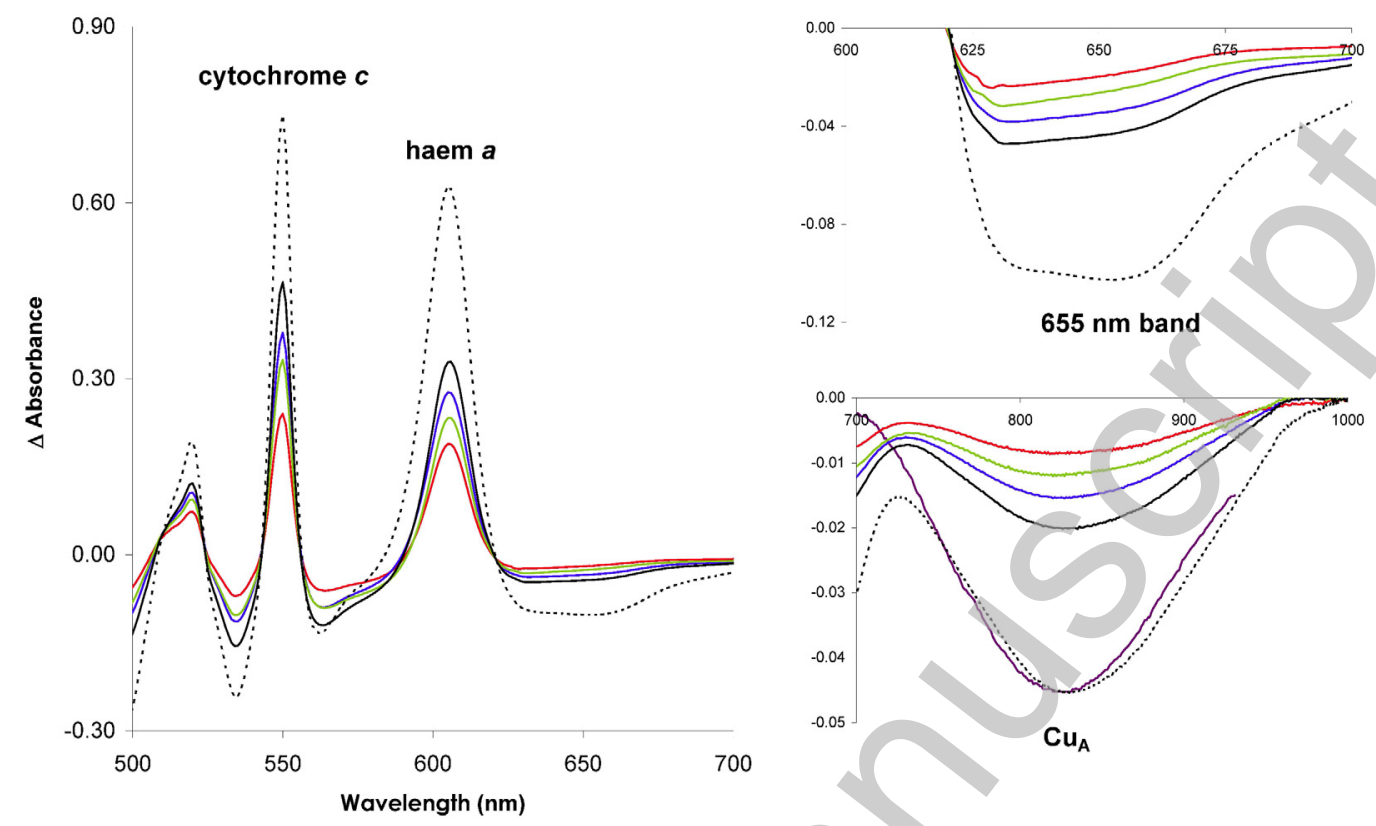

Figure 6 Cytochrome $c$ oxidase steady state difference spectra at different levels of reduction.

Solid lines are difference spectra of different steady states minus a very slow turnover steady state in which cytochrome $\mathrm{c}$ reduction is barely perceptible. The dashed line is the fully reduced minus slow turnover steady state difference spectrum. The expanded NIR region showing the $\mathrm{Cu}_{\mathrm{A}}$ spectrum is overlaid (purple solid line) with the reduced minus oxidized spectrum of $32 \mu \mathrm{M} \mathrm{Cu}$ domain from Thermus thermophilus ba subunit II $\mathrm{Cu}_{\mathrm{A}}$ [35], red-shifted by $34 \mathrm{~nm}$. Enzyme concentrations were cytochrome $c$ oxidase $32 \mu \mathrm{M}$, cytochrome $c 50 \mu \mathrm{M}$. Spectra were collected using an Ocean Optics S1024DWX diode array detector. Other conditions as described in experimental.

Licenced copy. Copying is not permitted, except with prior permission and as allowed by law. 


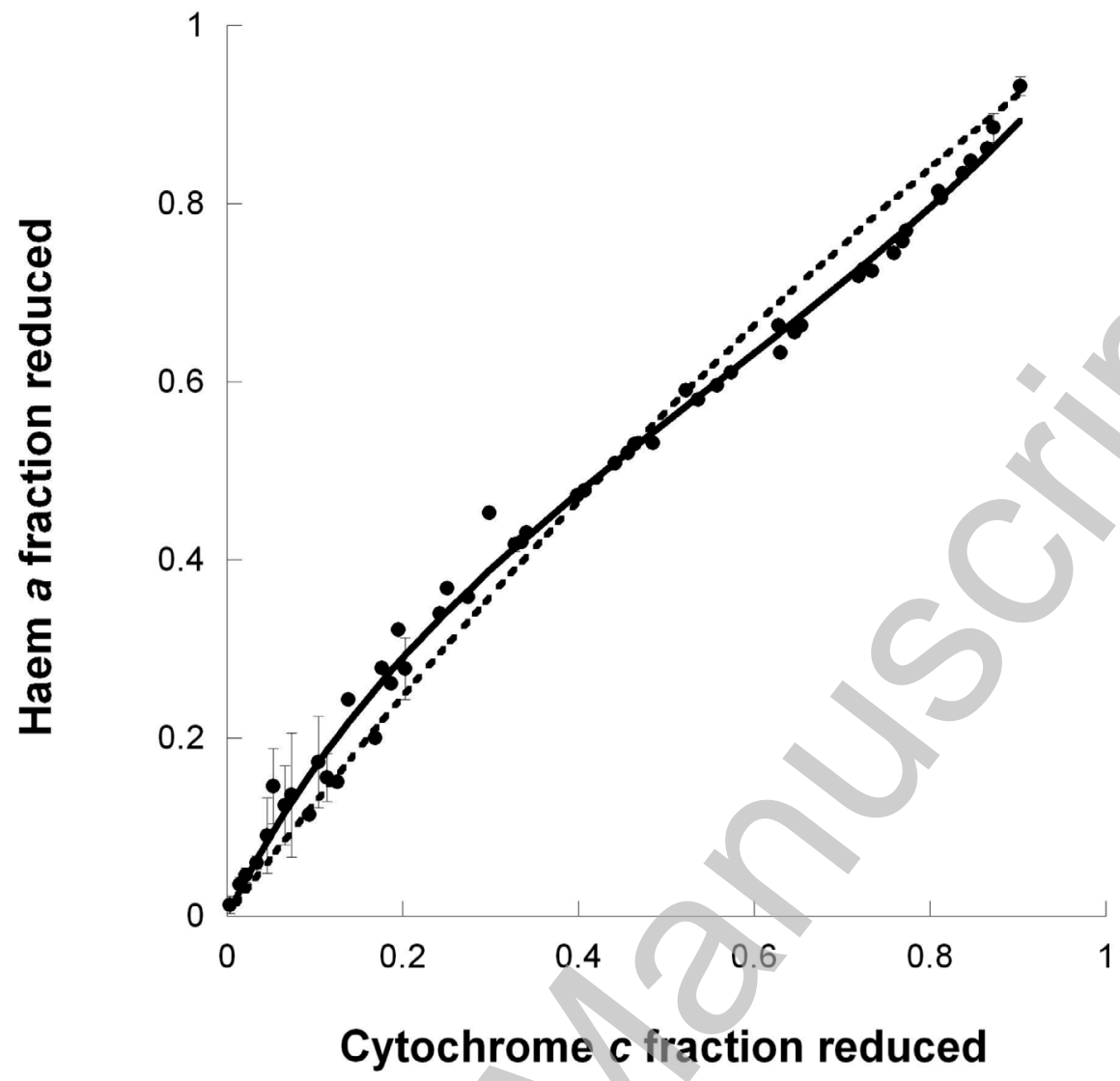

Figure 7 Equilibrium plot of steady state haem a redox levels

Data were fitted to one (dashed line) or two (solid line) components. The fit line for one component is clearly worse than the two component fit. Values for proportions of each component together with $\mathrm{E}_{0}{ }^{\prime}$ values are shown in table 2 .

Licenced copy. Copying is not permitted, except with prior permission and as allowed by law. 


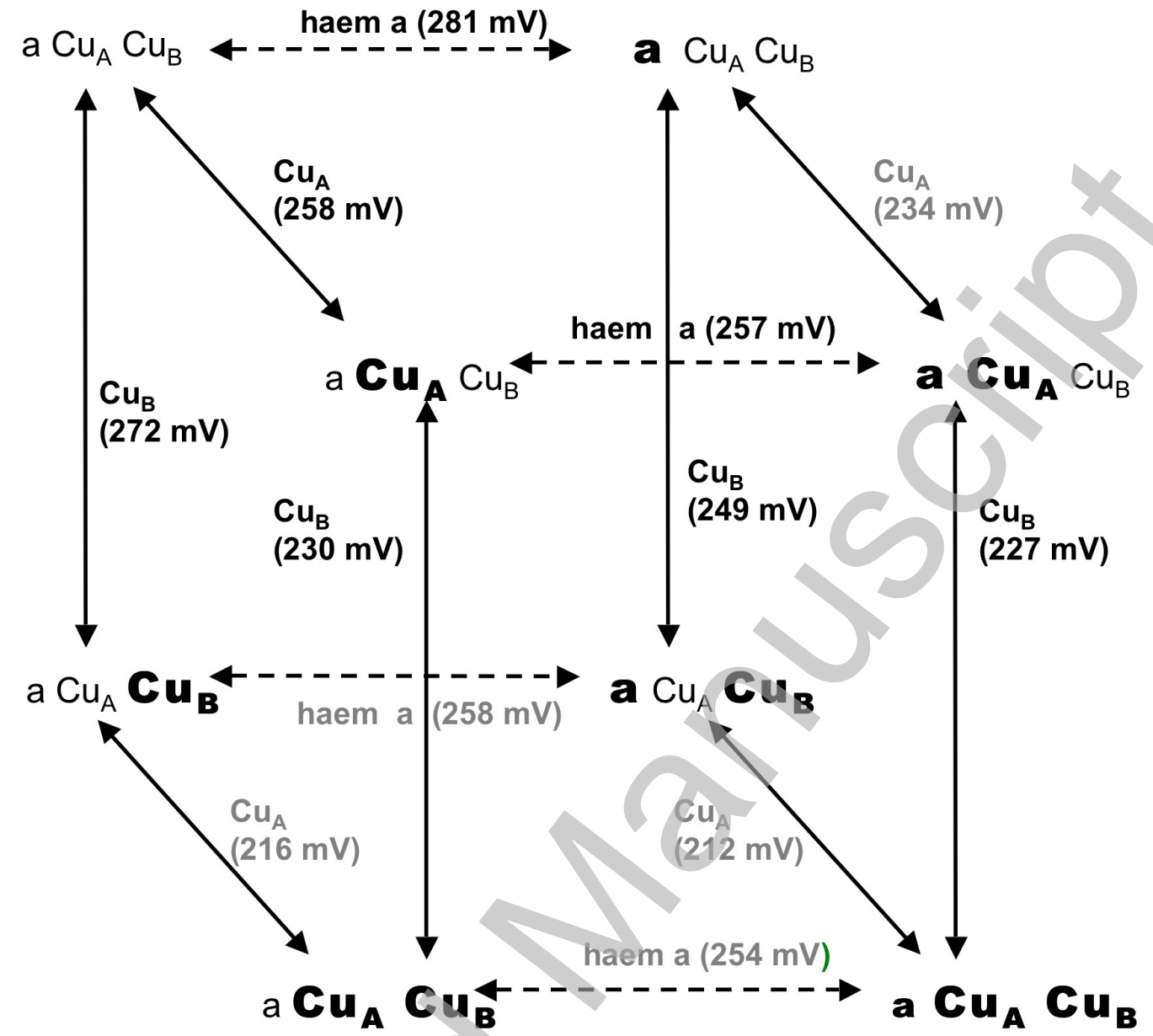

Redox potentials $(\mathrm{mV})$ for the centres in the 4 different redox states

\begin{tabular}{c|ccccc} 
Centre & Both oxidized & a reduced & $\mathrm{Cu}_{\mathrm{A}}$ reduced & $\mathrm{Cu}_{\mathrm{B}}$ reduced & Both reduced \\
\hline $\mathrm{Cu}_{\mathrm{A}}$ & 258 & 234 & --- & 216 & 212 \\
haem a & 281 & --- & 257 & 258 & 254 \\
$\mathrm{Cu}_{\mathrm{B}}$ & 272 & 249 & 230 & --- & 227
\end{tabular}

\section{Figure 8 Model for interactions between three species}

Model illustrating the equilibria assuming all three redox centres, haem $a, \mathrm{Cu}_{\mathrm{A}}$ and $\mathrm{Cu}_{\mathrm{B}}$, interact. Redox potentials were calculated as described in the experimental section with the resulting fit illustrated in Figure 9. Fonts in bold indicate reduction of a redox centre. The potentials in black were the minimal number (7) required to vary in the fit; the remaining potentials (in grey) were then calculated from the diagram above. It is assumed that the experimental reduction of the $655 \mathrm{~nm}$ band indicates $\mathrm{Cu}_{\mathrm{B}}$ reduction.

Licenced copy. Copying is not permitted, except with prior permission and as allowed by law. 


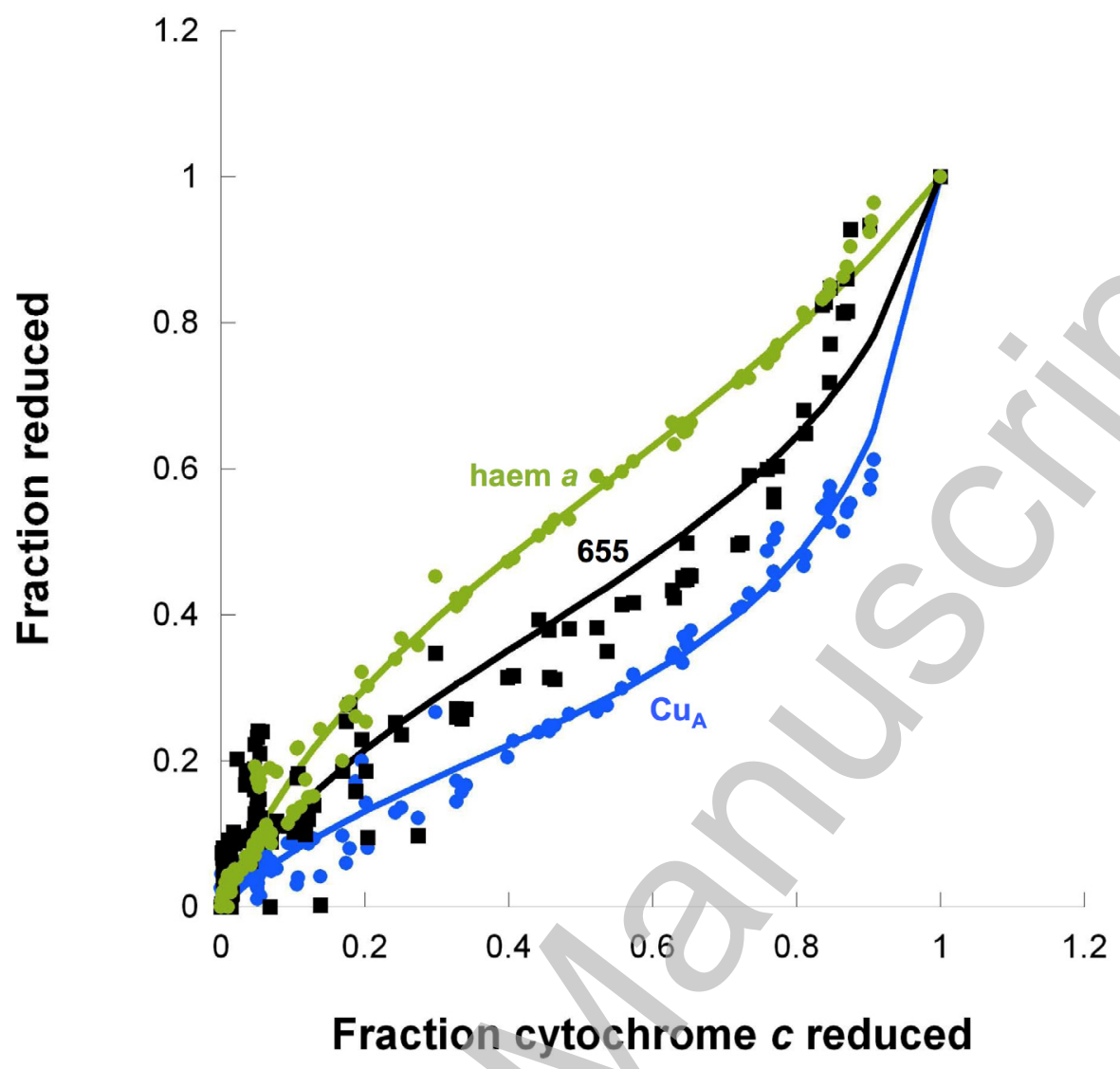

Figure 9 Combined equilibrium plot of steady state redox levels

Experimental data for all three cytochrome $c$ oxidase redox centres fitted to the model in Figure 9, which has three interacting redox potentials for each redox centre (see Fig. 8 and experimental section). 